\title{
Design of the Height of Antiglare Panels along Concave Vertical Curves
}

\author{
Guo-hua Liang $\left(\mathbb{D},{ }^{1}\right.$ Chen-hao Dong $\left(\mathbb{D},{ }^{1,2}\right.$ Yu Li $(D),{ }^{1}$ Ge Li $\left(D,{ }^{1}\right.$ \\ Xiao-xia $\mathrm{Hu}\left(\mathbb{D},{ }^{1}\right.$ and Li-zhong Cui $\mathbb{D}^{1}$ \\ ${ }^{1}$ School of Highway, Chang'an University, Xi'an, Shaanxi 710064, China \\ ${ }^{2}$ Xian City Planning \& Design Institute, Xian, Shaanxi 710064, China \\ Correspondence should be addressed to Yu Li; 745689758@qq.com
}

Received 12 October 2017; Revised 4 March 2018; Accepted 8 March 2018; Published 19 April 2018

Academic Editor: Ivano Benedetti

Copyright (C) 2018 Guo-hua Liang et al. This is an open access article distributed under the Creative Commons Attribution License, which permits unrestricted use, distribution, and reproduction in any medium, provided the original work is properly cited.

\begin{abstract}
This study introduces a method for calculating the height of antiglare panels for concave vertical curves. The concave vertical curve is divided into a straight-slope section, transition section, and middle section. The height of the antiglare panels in the middle section is designed based on the glare distance. The height in the straight-slope section is designed based on the height calculation formula given by the Chinese standard. The height of the antiglare panels in the middle section is greater than that in the straight-slope section. There should be a gradual transition in the height difference of the antiglare panels in the transition section. The height gradient of the antiglare panels in the transition section must be designed to ensure visual continuity and comfort for drivers. In the transition section, the transition design is carried out on the height difference of the antiglare panels using the UC-Win/Road simulation software to determine the acceptable height difference for drivers. When the radius of the concave vertical curve does not exceed 30,000 m, the height of the antiglare panel is required to be designed, and the height difference should not exceed $6 \mathrm{~cm}$.
\end{abstract}

\section{Introduction}

Glare is the visual effect of scattering light within the eye caused by a high brightness object or a strong contrast light source in the field of view [1-3]. Glare affects cognitive performance which in the visual periphery is more susceptible to disturbances, and discomfort glare impairs peripheral visual performance [4]. The presence of glare leads to a significant reduction in the safety margin and the number of traffic accidents is much higher in the glare conditions than in the nonglare conditions [5].

At night, the headlamps of an oncoming vehicle may cause harmful glare that interferes with the sight of drivers [6]. Installing antiglare facilities along the road is an economical and feasible method for solving the glare problem caused by the headlamps of oncoming vehicles. Traditionally, antiglare facilities on a concave vertical curve road are identical in height to those on a straight road, which follows the standard. This design often results in light leakage on concave vertical curve roads because the antiglare facilities are too short, causing the dazzling phenomenon. Thus, the height of the antiglare facilities must be designed based on different freeway alignments.

Previous studies mainly considered the relationship between driving safety and antiglare facilities. In order to block the road users' view of activities that can be distracting, MUTCD recommends installing screen to discourage gawking and reduce headlight glare from oncoming motor vehicle traffic [7]. Drivers of heavy vehicle and light vehicle need different height of anti- dazzle fence, but both of them thought the fence should be made solid and that it should be made higher [8]. Discomfort glare has a discomforting effect and causes fatigue, disturbance, apprehension, and pain that reduce drivers' ability and driving safety [9]. To illustrate the effect of glare on drivers, a method was introduced to estimate the significant effect of glare from automobile headlamps, and a previous study showed that older drivers are more sensitive to glare than young drivers [10]. The driver's behaviors that deal with the impact of glare are different in different road 
conditions [11, 12]. A realistic headlight glare simulator is developed to study the effects of glare during driving at night [13]. Moreover, a study was performed to verify the AdrianSchreuder formula, which is an effective measure for relieving the driving discomfort caused by glare on highways [14]. The danger of glare is reflected not only in the vehicles, but also in the train cabs [15]. The effects of smart advisory system (DSAS) messages on driving behaviors under the disturbance of sun glare were studied based on the half kinetic energy speed, average speed, brake response time, and braking distance [16]. By means of evaluating the impact of the antiglare screen, it is concluded that the accident rate (per/veh $/ \mathrm{km}$ ) on the screened length was 44 per cent lower than would have been expected had there been no screen at night [17]. By analyzing the characteristics of mixed traffic, in the combinations of different vehicles, antiglare plate height ranges between $1.15 \mathrm{~m}$ and $1.65 \mathrm{~m}$ [18]. Ohio began studying antiglare facilities in 1969. An expanded metal mesh was installed on guardrails and was later replaced by a concrete barrier. Installing these devices reduced the number of accidents by $35 \%$ [19].

Based on previous studies, many countries have introduced standards for the height of antiglare facilities, and different countries recommend different values. The existing standard in China states that the height of the antiglare facility should be $1.6-1.7 \mathrm{~m}$ on straight roads and $1.2-1.8 \mathrm{~m}$ on expressways combine flat and longitudinal highway alignments [20]. According to the research completed by Transportation Research Board, on a flat and level divided highway without cross-slope, glare screen would have to be the same height as the average driver's eye, or $1.14 \mathrm{~m}$, in accordance with AASHTO standards. But some of factors may require a somewhat greater height, such as horizontal curvature or vertical curvature [21]. Britain recommends a minimum height of $1.75 \mathrm{~m}$ for the glare screen to avoid the headlamp glare from all vehicles, including large trucks [22]. When glare screen is determined appropriate, the standard permanent glare screen is the $1.42 \mathrm{~m}$ tall [23]. In Ohio, a height model of the glare screen was developed based on the lateral position of the vehicle [24]. Roadway Design Manual of NCDOT recommends several criteria for use of glare screens: opposing traffic with $6.09 \mathrm{~m}$ or less of separation should be highly considered for using a glare screen; traffic separated by $15.24 \mathrm{~m}$ or more will not need glare screens. And normal height should be $1.27 \mathrm{~m}$ and up to $2.03 \mathrm{~m}$ in sag verticals [25]. Based on a two-dimensional analysis, the recommended height of the glare screen barrier is $1.78 \mathrm{~m}$. In Japan, Kodan recommended a glare screen height of $1.4 \mathrm{~m}$ for national expressways [26]. In India, a simplified model was developed and indicated that the height of the antiglare screen should be $1.76-1.81 \mathrm{~m}$ for four-lane and eight-lane highways and $1.79 \mathrm{~m}$ for six-lane divided highways [27]. A study shows that to be effective in screening the lights from all types of vehicle (including heavy commercials), the screen must reach to at least $1.73 \mathrm{~m}$ above the carriageway [28]. Although different countries recommend different heights for antiglare facilities, they do not consider the effects of different freeway alignments on the effectiveness of the antiglare facilities.
Currently, scholars are beginning to study the height of antiglare facilities along different freeway alignments. According to the studies on traffic safety facilities around roads, a new concept was introduced, namely, that the height of the antiglare facilities should vary for different road alignments [29]. Indian scholars used a three-dimensional analysis method that included plane, parabolic, and spherical surfaces, and they found that the height of the antiglare facilities should differ for different highway alignments [30]. Since then, many methods have been established for calculating the height of antiglare facilities, such as a model to calculate the height of antiglare facilities in different vertical roads, a model to calculate the height of antiglare facilities based on the dazzling longitudinal distance, and a method to determine the height of antiglare facilities in concave vertical curved sections based on a series of parameters, such as the radius of the concave vertical curve and the height of the headlamps [31-33]. However, increasing the height of the glare facilities along a concave vertical curve may cause a height difference between the straight-slope section and the concave vertical curved section, and this height difference may have a negative effect on driving comfort. Previous studies neglected the effect of such a height difference.

In this paper, a concave vertical curve is divided into three parts: the straight-slope section, transition section, and middle section; we focus on the middle section and transition section. The height of the antiglare panels in the straight-slope section is the value recommended by the design standard. In the middle section, a method for determining the height of the antiglare panels based on the glare distance is introduced. For the transition section, the height of the antiglare panels is designed by considering the visual characteristics of drivers.

\section{Methodology}

2.1. Design Idea. When approaching vehicles meet at different heights in a concave vertical curve, the height of the headlamps may be above the antiglare facilities, resulting in the antiglare facilities being unable to satisfy the requirement, as shown in Figure 1. Therefore, the height of antiglare facilities for a concave vertical curve should be recalculated according to the curve's radius and longitudinal slope. This recalculated height for the antiglare facilities differs greatly from the height for a straight road, and this difference may cause visual abruptness and psychological discomfort to drivers.

Therefore, the concave vertical curve is divided into three parts: the straight-slope section, transition section, and middle section. The influence of the height difference on the drivers is eliminated by gradually adjusting the height of the antiglare facilities in the transition section. To provide convenience in practical operation, the transition section is segmented and denoted as a, b, c, and so on, as shown in Figure 1.

The height of the antiglare facilities in the straight-slope section is $h$ and is calculated using the formula for antiglare facilities provided in the Guidelines for Design of Highway Safety Facilities [34]. $H$ is the height of the antiglare panels in the middle section, which is calculated based on the longitudinal distance of the glare. In the transition section, the gradient is designed for visual continuity and comfort of the drivers. 


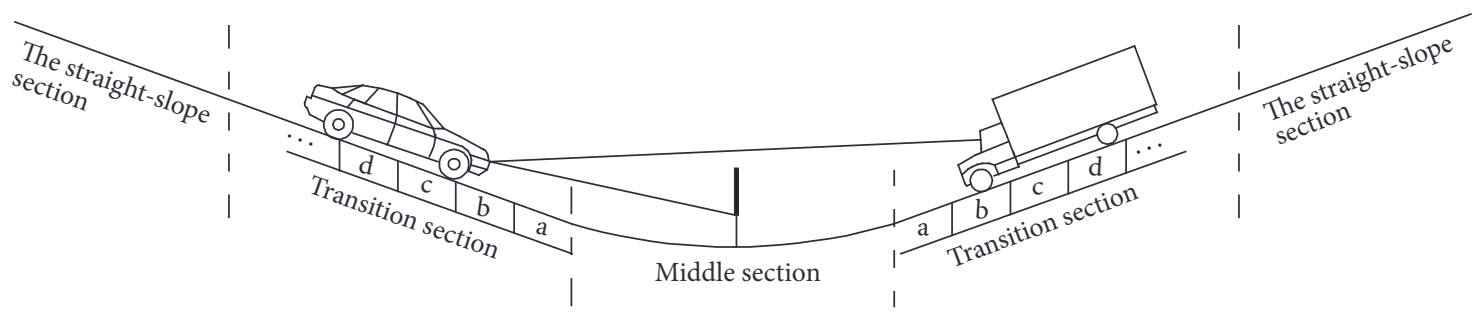

Figure 1: Division of the concave vertical curve.

2.2. Height of the Antiglare Panels in the Straight-Slope Section. In the Guidelines for Design of Highway Safety Facilities [34], $h$ is calculated as follows:

$$
\begin{aligned}
& h=h_{1}+\frac{\left(h_{2}-h_{1}\right)}{\left(B_{1}+B_{2}\right)}, \\
& B=B_{1}+B_{2},
\end{aligned}
$$

where $h$ is the height of the antiglare panels in the straightslope section; $h_{1}$ is the headlamp height of the car; $h_{2}$ is the height of the driver's sight line; $B_{1}$ and $B_{2}$ are the distance between the car and the antiglare panels of the current lane and opposite lane, respectively; and $B$ is the sum of the distances between the centerline of the vehicles on both road sides and the antiglare panels. The calculation method of height of the antiglare panels is shown in Figures 2(a) and 2(b), where $\alpha$ and $\beta$ are the deflection angle and shielding angle of the antiglare panels, respectively.

Eqs. (1) imply that the height of the antiglare panels in the straight section is only related to the height of the headlamp, the height of the driver's sight line, and the lane position. To satisfy the antiglare functionality and the height requirements of all lane combinations, the most unfavorable conditions should be considered when calculating the height of the antiglare panels in the straight-slope section. Therefore, a truck should be assumed to be in lanes 2 and 4, as shown in Figure 2(a). Based on the Chinese national standards, when the model is truck, the height of the headlamps $\left(h_{1}\right)$ is $1 \mathrm{~m}$, and the height of the driver's sight line $\left(h_{2}\right)$ is $2 \mathrm{~m}$; a freeway lane is $3.75 \mathrm{~m}$ wide, a curb band is $0.75 \mathrm{~m}$ wide, the antiglare panels are set in the median divider, and the partition is $2 \mathrm{~m}$ wide. Thus, $B_{1}$ is $7.375 \mathrm{~m}$, and $B$ is $11.00 \mathrm{~m}$. According to the equation, the height of the antiglare panels in the straightslope section is $1.67 \mathrm{~m}$.

2.3. Height of the Antiglare Panels in the Middle Section. The middle section of the concave vertical curve is a circular curve. The projection curve of the headlamp trajectory and the driver's sight line trajectory on the road profile is a group of concentric circles. The headlamps should be designed so that drivers can see a traffic barrier $120 \mathrm{~m}$ in front of the vehicle; thus, the irradiation distance of headlamps is $120 \mathrm{~m}$.

In Figure 2(c), we assume that the radius of the vertical section profile is $R$, the radius of the automobile headlamp is $R_{1}$, the radius of the driver's sight line trajectory is $R_{2}$, and $O_{1}$ is the center of the curves. Assume that in the section of the concave vertical curve within the range of the automobile

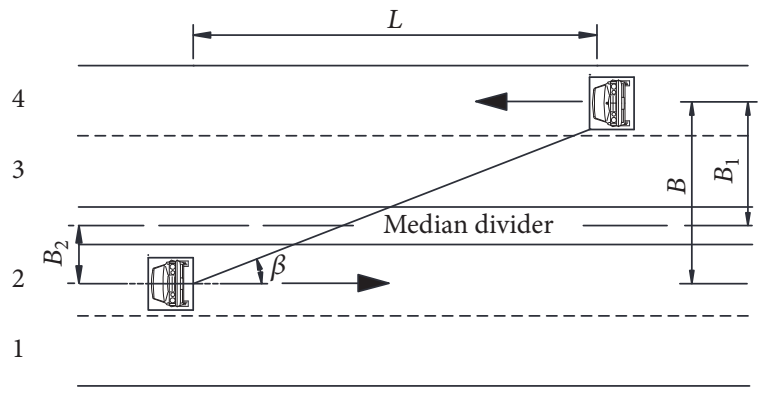

(a) Lane distribution

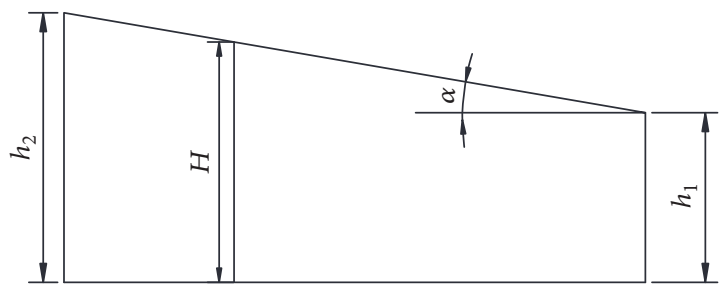

(b) Schematic for calculating the height of the antiglare panels

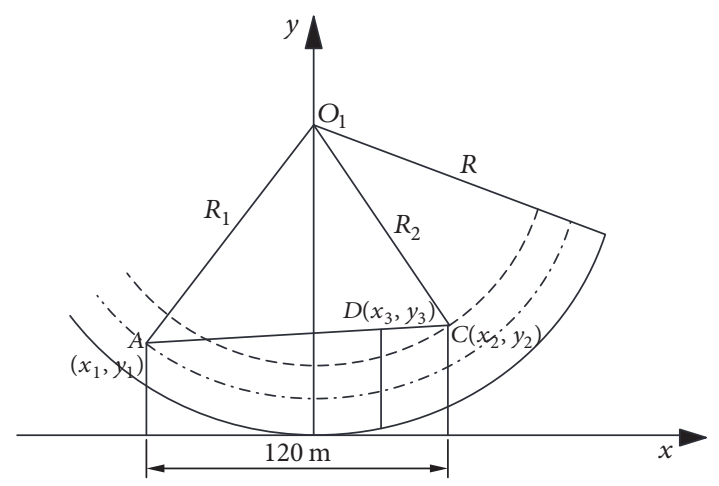

(c) Height calculation of the antiglare panels in the middle section

FIGURE 2: Setting the height of the antiglare panels.

headlamps, the drivers are always in the glare zone and that the projection length of the headlamps is approximately equal to the irradiation distance in the horizontal direction. Taking $X$ as the horizontal axis and $Y$ as the vertical axis, for the automobile headlamp position of vehicle $A\left(x_{1}, y_{1}\right)$, the farthest point affected by glare that the driver can see is $C$ $\left(x_{2}, y_{2}\right)$. The position of antiglare panels is $D\left(x_{3}, y_{3}\right)$, and $B_{1}$ and $B_{2}$ are the distance between the car and antiglare panels 
of the current lane or the opposite lane, where $B=B_{1}+B_{2}$. The abscissa of points $A, C$, and $D$ are

$$
\begin{aligned}
& x_{2}=x_{1}+120, \\
& x_{3}=x_{1}+\frac{120 B_{1}}{B} .
\end{aligned}
$$

The equation of the curved road section is

$$
x^{2}+(y-R)^{2}=R_{1}^{2} .
$$

The projection equation of the trajectory of the headlamps on the road profile is

$$
\begin{aligned}
x_{1}+\left(y_{1}-R\right)^{2} & =R^{2}, \\
R_{1} & =R-h_{1} .
\end{aligned}
$$

The projection equation of the driver's sight line in the longitudinal section is

$$
\begin{aligned}
x_{2}+\left(y_{2}-R\right)^{2} & =R_{2}^{2}, \\
R_{2} & =R-h_{2} .
\end{aligned}
$$

At point $D$, to satisfy the antiglare function, the vertical axis of antiglare panels is

$$
y_{3}=y_{1}+\frac{\left(y_{2}-y_{1}\right) B_{1}}{B} .
$$

In summary, at point $D$ in the concave vertical curve, to satisfy the antiglare function, the height of antiglare panels $H_{1}$ is

$$
\begin{aligned}
H_{1}= & y_{3}-y \\
= & \sqrt{R^{2}-x_{3}^{2}}-\sqrt{\left(R-h_{1}\right)^{2}-\left(x_{3}-\frac{120 B_{1}}{B}\right)^{2}} \\
& +\frac{\left[\sqrt{\left(R-h_{1}\right)^{2}-\left(x_{3}-120 B_{1} / B\right)^{2}}-\sqrt{\left(R-h_{2}\right)^{2}-\left(x_{3}+120-120 B_{1} / B\right)^{2}}\right] B_{1}}{B} .
\end{aligned}
$$

A reasonable height for the antiglare facilities should follow a symmetrical curve. In reality, antiglare facilities should be set by using (7) to calculate the height of antiglare facilities at the same distance on both sides and by rounding off the smaller value. In the coordinate system, there are two points where the horizontal distance is $d$ from the top of the concave vertical curve: $D_{1}\left(-d, y_{3}\right)$ and $D_{2}\left(d, y_{3}\right)$. The maximum height of antiglare panels is calculated as follows:

$$
\begin{aligned}
H \max = & H \\
= & \sqrt{R^{2}-d^{2}}-\sqrt{\left(R-h_{1}\right)^{2}-\left(d+\frac{120 B_{1}}{B}\right)^{2}} \\
& +\frac{\left[\sqrt{\left(R-h_{1}\right)^{2}-\left(d+120 B_{1} / B\right)^{2}}-\sqrt{\left(R-h_{2}\right)^{2}-\left(120-d-120 B_{1} / B\right)^{2}}\right] B_{1}}{B} .
\end{aligned}
$$

According to (8), the height of antiglare panels in the middle section of the concave vertical curve is related to the height of the headlamps $\left(h_{1}\right)$, the height of the driver's sight line $\left(h_{2}\right)$, the vehicle position $\left(B_{1}\right),(B)$, and the distance $(d)$ from the top of the circular curve to the vehicle, where $d$ is determined from the longitudinal slope. When the radius, vehicle type, and lane position are known, the height of the antiglare panels is dependent on only the longitudinal slope. According to the Technical Standard of Highway Engineering [35], for straight slopes, when the car speed is 120,100 , and $80 \mathrm{~km} / \mathrm{h}$, the maximum longitudinal slope is $3 \%, 4 \%$, and $5 \%$, and the minimum radius is $4,000,3,000$, and $2,000 \mathrm{~m}$, respectively. The height of the antiglare panels is calculated for the middle section at different radii from the minimum radius until the height is equal to that of the antiglare panels in the straight-slope section. The results are shown in Table 1, where $h$ is the height of the antiglare panels in the straight segment, $H$ is the height of the antiglare panels in the middle segment, and $\Delta H$ is the height difference between the straight segment and the middle segment.

Table 1 shows that, for a given radius, the height of the antiglare panels is approximately the same for different speeds, which indicates that the slope gradient does not greatly affect the height of the antiglare panels. The height of 
TABLE 1: Design height of the antiglare panels in the intermediate segment with radii of 2,000-700,000 m.

\begin{tabular}{|c|c|c|c|c|c|c|c|}
\hline \multirow{2}{*}{$\begin{array}{l}\text { Speed } \\
\text { Radius }\end{array}$} & \multirow{2}{*}{$h$} & \multicolumn{2}{|c|}{$80 \mathrm{~km} / \mathrm{h}$} & \multicolumn{2}{|c|}{$100 \mathrm{~km} / \mathrm{h}$} & \multicolumn{2}{|c|}{$120 \mathrm{~km} / \mathrm{h}$} \\
\hline & & $H$ & $\Delta H(\mathrm{~m})$ & $H$ & $\Delta H(\mathrm{~m})$ & $H$ & $\Delta H(\mathrm{~m})$ \\
\hline 2,000 & 1.67 & 2.47 & 0.80 & -- & -- & -- & -- \\
\hline 3,000 & 1.67 & 2.21 & 0.54 & 2.20 & 0.53 & -- & -- \\
\hline 4,000 & 1.67 & 2.07 & 0.40 & 2.07 & 0.40 & 2.07 & 0.40 \\
\hline 5,000 & 1.67 & 1.99 & 0.32 & 1.99 & 0.32 & 1.99 & 0.32 \\
\hline 6,000 & 1.67 & 1.94 & 0.27 & 1.94 & 0.27 & 1.94 & 0.27 \\
\hline 7,000 & 1.67 & 1.90 & 0.23 & 1.90 & 0.23 & 1.90 & 0.23 \\
\hline 8,000 & 1.67 & 1.87 & 0.20 & 1.87 & 0.20 & 1.87 & 0.20 \\
\hline 9,000 & 1.67 & 1.85 & 0.18 & 1.85 & 0.18 & 1.85 & 0.18 \\
\hline 10,000 & 1.67 & 1.83 & 0.16 & 1.83 & 0.16 & 1.83 & 0.16 \\
\hline 15,000 & 1.67 & 1.78 & 0.08 & 1.78 & 0.08 & 1.78 & 0.08 \\
\hline 20,000 & 1.67 & 1.75 & 0.08 & 1.75 & 0.08 & 1.75 & 0.08 \\
\hline 25,000 & 1.67 & 1.74 & 0.07 & 1.74 & 0.07 & 1.73 & 0.06 \\
\hline 30,000 & 1.67 & 1.73 & 0.06 & 1.72 & 0.05 & 1.72 & 0.05 \\
\hline 35,000 & 1.67 & 1.72 & 0.05 & 1.72 & 0.05 & 1.72 & 0.05 \\
\hline 40,000 & 1.67 & 1.71 & 0.04 & 1.71 & 0.04 & 1.71 & 0.04 \\
\hline 45,000 & 1.67 & 1.71 & 0.04 & 1.71 & 0.04 & 1.71 & 0.04 \\
\hline 50,000 & 1.67 & 1.70 & 0.03 & 1.70 & 0.03 & 1.70 & 0.03 \\
\hline 55,000 & 1.67 & 1.70 & 0.03 & 1.70 & 0.03 & 1.70 & 0.03 \\
\hline 60,000 & 1.67 & 1.70 & 0.03 & 1.70 & 0.03 & 1.70 & 0.03 \\
\hline 65,000 & 1.67 & 1.70 & 0.03 & 1.70 & 0.03 & 1.70 & 0.03 \\
\hline 70,000 & 1.67 & 1.69 & 0.02 & 1.69 & 0.02 & 1.69 & 0.02 \\
\hline 200,000 & 1.67 & 1.68 & 0.01 & 1.68 & 0.01 & 1.68 & 0.01 \\
\hline 500,000 & 1.67 & 1.68 & 0.01 & 1.67 & 0.00 & 1.67 & 0.00 \\
\hline 700,000 & 1.67 & 1.67 & 0.00 & & & & \\
\hline
\end{tabular}

the antiglare panels decreases with increasing radius of the vertical curve; when the vertical curve radius is greater than $50,000 \mathrm{~m}$, the height change of the antiglare panels is quite small, and the height of the antiglare panels is similar to the height for the straight-slope section, which is $1.67 \mathrm{~m}$.

2.4. Height of the Antiglare Panels in the Transition Section. The height of the antiglare panels in a concave vertical curve should not affect the drivers' visual comfort by greatly increasing in the middle section. Therefore, the height in the middle section should gradually transition to that in the straight-slope section of the concave vertical curve to improve the drivers' visual comfort.

The starting point of the transition section is set at the extreme point of the curve, and the end point is set at the straight-slope section. The transition section is divided into several segments. According to the Chinese standard Guidelines for Design of Highway Traffic Safety Facilities [34], when the structural form, height, and position are variable, the gradual transition section should be constant, so the appropriate length of each segment is $50 \mathrm{~m}$, as shown in Figure 1.

The length of the transition section $(L)$ and the number of transition section segments $(N)$ according to the height difference $(\Delta h)$ of the antiglare panels of each segment in the transition section. The equations are as follows:

$$
\begin{aligned}
& N=\frac{H-h}{\Delta h}, \\
& L=50 N .
\end{aligned}
$$

The height difference $(\Delta h)$ of the antiglare panels depends on the drivers' visual experience. The road, traffic, environment, and other factors affect the visual experience. Due to continuously changing the height of antiglare panels in an actual project being not feasible, simulation experiments were performed which can introduce visual experience that is similar to driving on an actual road. When $\Delta h$ and $N$ are determined, the height of antiglare panels in each segment can be calculated.

2.5. Simulation Modeling. In this paper, a road landscape simulation software called UC-Win/Road was used to perform simulation experiments, and a questionnaire survey was conducted to determine the optimum height difference $\Delta h$ of the antiglare panels for each transition segment.

The simulation modeling needs the UC-Win/Road software and its accompanying driving simulator. The driver controls the driving simulation scenarios (including the road environment and the driver's operation scene) and driving simulator by operating the steering wheel, brake, and throttle with a force feedback system and so on. The image displays on three screens in a $135^{\circ}$ field of view and is equipped 
with an audio output of the outside sound. Thus, the driver experiences audio-visual effects similar to driving on an actual road. There are 4 steps for simulation modeling.

Step 1. Load terrain: import an XML file using a custom terrain based on a $50 \mathrm{~m}$ grids, and then edit terrain. Determine the terrain according to the experimental requirements.

Step 2. Define road: firstly, select concave vertical curve section in 4-lane dual freeway; the pedestal of antiglare panels is designed to be $0.8 \mathrm{~m}$ high; lane width is $3.75 \mathrm{~m}$, shoulder width is $0.75 \mathrm{~m}$, the left curb width is $0.75 \mathrm{~m}$, and traffic marking width is $0.15 \mathrm{~m}$. Secondly, define horizontal alignment and determine the length of the road, radii of the curve, the length of curve, and direction change point of concave vertical curves. Thirdly, define the road vertical section and determine the starting point, the changing point, and the end point of concave vertical curves.

Step 3. Arrange environment models and enhance 3D effects: create antiglare panel model by using of 3DSMAX; then set its material, color, height, and other parameters. Create background according to the actual situation, setting traffic volume.

Step 4. Real time virtual reality simulation: determine vehicle types, driving lanes, design speed, and weather conditions to simulate vehicle driving according to the environment set previously.

\subsection{Procedure}

\subsubsection{Determination of the Simulation Parameters}

(1) Road. To simplify the experimental process, a 4-lane dual freeway was selected as the research road. According to the Technical Standard of Highway Engineering [35], for roads with design speeds of 120,100 , and $80 \mathrm{~km} / \mathrm{h}$, the corresponding maximum longitudinal slopes are $3 \%, 4 \%$, and $5 \%$, and the minimum radii are 4,000, 3,000, and $2,000 \mathrm{~m}$, respectively. Otherwise, according to the above discussion, when the concave vertical curve radius is equal to or greater than $700,000 \mathrm{~m}$, the height of the antiglare panels in the middle section is equal to that in the straight section, so the concave vertical curve radius which needs to be analyzed does not exceed 700,000 m.

(2) Design Speed. According to the Regulation on the Implementation of the Road Traffic Safety Law of the People's Republic of China, the maximum speed of cars on the freeway should not exceed $120 \mathrm{~km} / \mathrm{h}$, and the speed of other motor vehicles should not exceed $100 \mathrm{~km} / \mathrm{h}$. Because there are at least two lanes in one direction, the minimum speed of cars in the left lane is $100 \mathrm{~km} / \mathrm{h}$, and trucks are not permitted to travel in the inside lane of the freeway for long periods of time. Thus, the simulations of large vehicles are performed in the lateral lane.

(3) The Sight Line Heights. We selected a car and a truck as the simulation objects. The sight line heights of the truck driver and car driver are $2 \mathrm{~m}$ and $1.3 \mathrm{~m}$, respectively, and the headlamp heights of the truck and car are $1 \mathrm{~m}$ and $0.8 \mathrm{~m}$, respectively.

(4) Other Parameters. The simulation experiment was run during the day and at night. The pedestal of the antiglare panels was designed to be $0.8 \mathrm{~m}$ high, and the antiglare panels were spaced $1 \mathrm{~m}$ apart. The antiglare panels were colored green, which is common in China.

2.6.2. Preliminary Simulation Experiments. One hundred subjects (drivers) participated in the driving simulation experiment. The main inclusion criteria were valid driving licenses, normal vision, and contrast sensitivity. The sample of the present study comprised 77 males and 23 females who had been driving for 1-12 years (mean: 5.24). There are 3,216,000 simulation programs for different vehicle types, lanes, road radii, design speeds, height differences, and subjects. To reduce the number of tests, preliminary experiments used the comparative analysis to determine the most unfavorable conditions for a driver's visual perception of the height difference by which accurate survey data can be attained. Aimed to understand the driver's visual perception in the conditions of various height differences of antiglare panels, the initial height difference $(\Delta h)$ of each segment was $1 \mathrm{~cm}$, and $\Delta h$ was increased by $1 \mathrm{~cm}$ for each new simulation experiment. The results obtained are shown in Figure 3(a). The abruptness degree is defined as the proportion of all experimenters who can significantly perceive the change in the height of the antiglare panels when the $\Delta h$ is determined.

The conditions of the control group in the preliminary experiment are good weather during the day, standard bidirectional four-lane freeway, $8 \mathrm{~cm}$ of height difference, a design speed of $100 \mathrm{~km} / \mathrm{h}, 4000 \mathrm{~m}$ of concave vertical curve radius, outside lane, and car. In the case of other unchanged conditions, in the experimental group 1, the radius is $10000 \mathrm{~m}$; in the experimental group 2, the vehicle types is truck; in the experimental group 3, vehicles run in inside lane; in the experimental group 4, the design speed is $120 \mathrm{~km} / \mathrm{h}$; in the experimental group 5, vehicles run at night. Each experiment has 10 subjects. The 100 subjects observed and recorded their feelings about the abruptness degree at various height differences until the height difference is too high to tolerate in the conditions of the control group and the experimental group 1-5. Compared with the control group, the abruptness degree of drivers in experimental groups may be weaker, unchanged, or stronger, as shown in Figure 3(b).

The preliminary simulation tests indicated that the drivers' visual perception of the height difference was mainly affected by illumination, speed, vehicle type, and lane. The drivers were generally more sensitive to the height difference of the antiglare panels at night than during the daytime, and the drivers were able to sense more strongly when the vehicle went uphill than when the vehicle went downhill. The drivers' perception of the height differences was greater in larger vehicles than in smaller vehicles. The drivers were more sensitive to the height difference when driving in the inside lane than in the outside lane and when driving at lower speeds. Changing the radius of the concave vertical curve and 


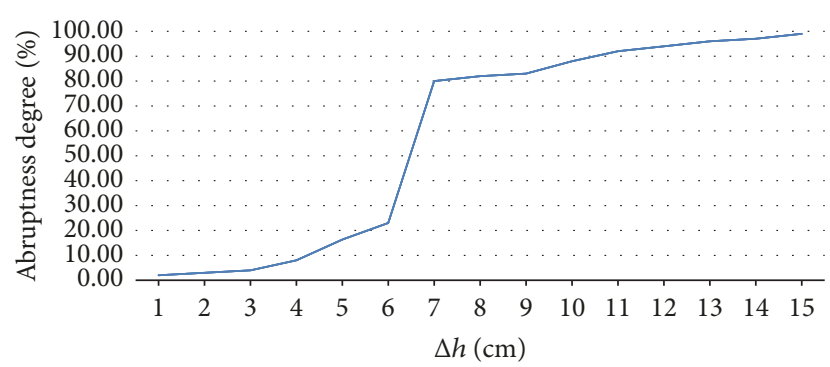

(a) Drivers' abruptness degree at various height differences

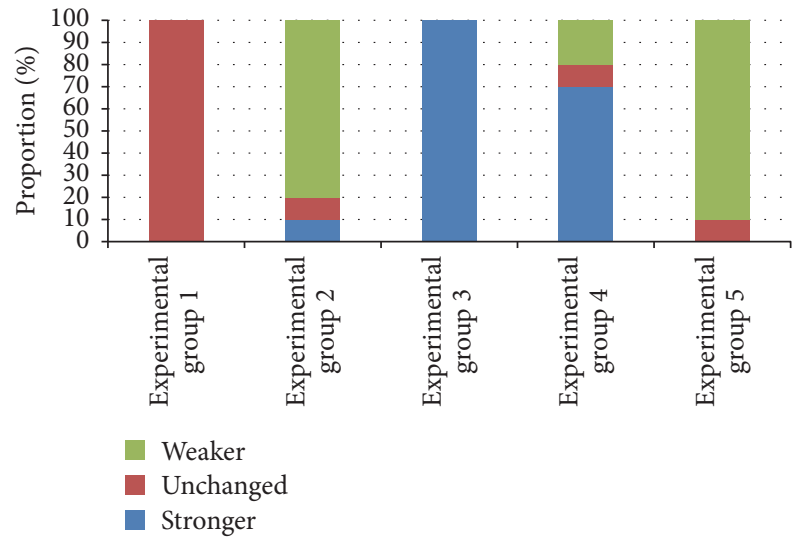

(b) The comparison of driver's abruptness sense between control group and experimental groups

FIGURE 3: Data analysis of preliminary experiments.

the vertical slope of the longitudinal slope did not affect the drivers' visual perception. The drivers scarcely felt any change when the height difference was $1-3 \mathrm{~cm}$ and felt a strong feeling of abruptness when the height difference was $10 \mathrm{~cm}$.

2.6.3. Determination of the Simulation Programs. According to the preliminary simulation test, the most unfavorable factors were selected to simplify the simulation program. The four programs are as follows.

Program 1. It has good weather during the day and standard bidirectional four-lane freeway; the design speed is $120 \mathrm{~km} / \mathrm{h}$; the concave vertical curve radius is $4,000 \mathrm{~m}$; the longitudinal slope in the transition section is $3 \%$; it happens in inside lane; there is a car.

Program 2. It has good weather during the day and standard bidirectional four-lane freeway; the design speed is $100 \mathrm{~km} / \mathrm{h}$; the concave vertical curve radius is $3,000 \mathrm{~m}$; the longitudinal slope in the transition section is $4 \%$; it happens in inside lane; there is a car.

Program 3. It has good weather during the day and standard bidirectional four-lane freeway; the design speed is $80 \mathrm{~km} / \mathrm{h}$; the concave vertical curve radius is $2,000 \mathrm{~m}$; the longitudinal slope in the transition section is $5 \%$; it happens in inside lane; there is a car.

Program 4. It has good weather during the day and standard bidirectional four-lane freeway; the design speed is $80 \mathrm{~km} / \mathrm{h}$; the concave vertical curve radius is $2,000 \mathrm{~m}$; the longitudinal slope in the transition section is $5 \%$; it happens in inside lane; there is a truck.

According to the preliminary analysis, the height difference of the antiglare panels was selected to begin at $4 \mathrm{~cm}$. For each new simulation experiment, $\Delta h$ was increased by $4 \mathrm{~cm}$ until the height difference reached $10 \mathrm{~cm}$. One hundred subjects (drivers) who participated in the preliminary simulation experiments would carry out the driving simulation experiments. Therefore, each subject needs to observe and record the feeling about the height difference of the antiglare panels as it gradually transit from $4 \mathrm{~cm}$ to $10 \mathrm{~cm}$ in the above four different situations. The number of present experiments is 2800 .

2.6.4. Simulation Experiments. To avoid improper operation in the formal experiment, the drivers needed to know the operational method of the driving simulator and the operational performance of the steering wheel, brake and throttle. Before the formal experiment, the drivers completed simulations of acceleration, deceleration, uphill movement, and downhill movement according to the prompt information in the scene. The traffic flow was set to zero in this experiment so that the subjects were not be affected by the driving behavior of other vehicles in the driving simulation process. The effects of the vehicle speed, lane location, and vehicle type on the visual cognition of the drivers are useful for improving the accuracy of the data.

The experiments were run from when the car entered the transition section of the concave vertical curve, through the middle section, and ended at the transition section of the other side of the road. Each driver was presented with four group simulation programs. We recorded the visual perception of the driver regarding the height difference of the antiglare panels at the end of each driving simulation.

2.7. Statistical Analysis. Figure 4 shows the results obtained after analyzing the data collected from the four programs. This figure shows that the abruptness degree felt by the drivers follows similar trends in different programs. The average abruptness degrees for the four programs are $15.4 \%, 20.62 \%$, $37.21 \%, 79.34 \%, 82.19 \%, 83.38 \%$, and $90.23 \%$ for height differences of $4,5,6,7,8,9$, and $10 \mathrm{~cm}$, respectively. There is a large increase in the abruptness degree when the height difference is $6-7 \mathrm{~cm}$, and the drivers feel a similar degree of abruptness when the height difference is 8,9 , and $10 \mathrm{~cm}$. Therefore, the driver experiences a high degree of abruptness when the height difference is $7 \mathrm{~cm}$. Besides, taking convenience into account in the project, $6 \mathrm{~cm}$ was selected as the optimal height difference.

After the height difference of antiglare panels of the transition section was selected (Table 2), we used (9) to determine the number and length of transition segments for different concave vertical curve radii.

According to the Technical Standard of Highway Engineering [35], the length of the longitudinal slope of the freeway should be $200-1,100 \mathrm{~m}$. When the length of the transition section exceeds the length of the straight section because of the limits of local conditions, the height of the antiglare 


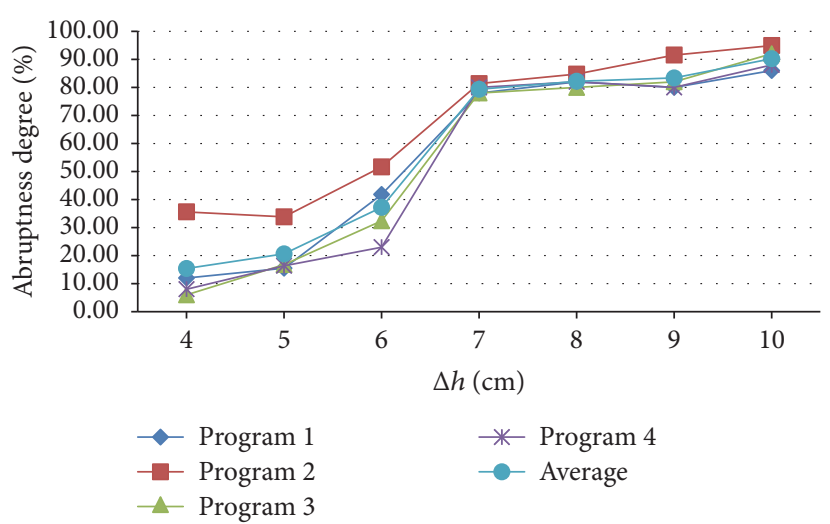

FIGURE 4: Abruptness degree of the antiglare panels at various height differences.

TABLE 2: Number $(N)$ and length $(L)$ of the transition sections for different concave vertical curve radii.

\begin{tabular}{|c|c|c|c|c|c|c|c|c|c|c|c|}
\hline \multirow{2}{*}{ Transition section } & \multicolumn{11}{|c|}{ Radius } \\
\hline & 2,000 & 3,000 & 4,000 & 5,000 & 6,000 & 7,000 & 8,000 & 9,000 & 10,000 & 20,000 & 30,000 \\
\hline $\bar{a}$ & 2.41 & 2.14 & 2.01 & 1.93 & 1.88 & 1.84 & 1.81 & 1.79 & 1.77 & 1.69 & - \\
\hline $\mathrm{b}$ & 2.35 & 2.08 & 1.95 & 1.87 & 1.82 & 1.78 & 1.75 & 1.73 & 1.71 & - & - \\
\hline$c$ & 2.29 & 2.02 & 1.89 & 1.81 & 1.76 & 1.72 & 1.69 & - & - & - & - \\
\hline d & 2.23 & 1.96 & 1.83 & 1.75 & 1.7 & - & - & - & - & - & - \\
\hline e & 2.17 & 1.9 & 1.77 & 1.69 & - & - & - & - & - & - & - \\
\hline $\mathrm{f}$ & 2.11 & 1.84 & 1.71 & - & - & - & - & - & - & - & - \\
\hline $\mathrm{g}$ & 2.05 & 1.78 & - & - & - & - & - & - & - & - & - \\
\hline $\mathrm{h}$ & 1.99 & 1.72 & - & - & - & - & - & - & - & - & - \\
\hline i & 1.93 & - & - & - & - & - & - & - & - & - & - \\
\hline j & 1.87 & - & - & - & - & - & - & - & - & - & - \\
\hline $\mathrm{k}$ & 1.81 & - & - & - & - & - & - & - & - & - & - \\
\hline 1 & 1.75 & - & - & - & - & - & - & - & - & - & - \\
\hline $\mathrm{m}$ & 1.69 & - & - & - & - & - & - & - & - & - & - \\
\hline (Number) $N$ & 13 & 8 & 6 & 5 & 4 & 3 & 3 & 2 & 2 & 1 & 0 \\
\hline (Length) $L$ & 650 & 400 & 300 & 250 & 200 & 150 & 150 & 100 & 100 & 50 & 0 \\
\hline
\end{tabular}

panels should transition within the straight road to satisfy the transition requirement. When the length of the straight section exceeds the length of the transition section, the transition section is designed based on the vertical concave curve section.

\section{Results}

(1) In the middle section of concave vertical curve section, the height of the antiglare panels is greater than that in the straight-slope section. It will affect drivers' visual comfort as height difference exceeds acceptable level. Thus, a transition section is necessary and the height of the antiglare panels in the transition section must be determined.

(2) The length of the transition section $L$ and the number of transition section segments $N$ are calculated from $\Delta h$. When the length of the transition section is greater than that of the straight-slope section, as determined by local conditions, the transition section must begin in the straight road to satisfy the visual comfort requirements of the drivers.
(3) The height of the antiglare panels is different for different concave vertical curve radii. For a smaller radius, the height difference is greater, the number of transition sections is larger, and the transition section is longer. When the radius of the concave vertical curve exceeds $20,000 \mathrm{~m}$, the freeway alignment is smooth, and a transition section is not necessary.

(4) Simulation results show that when the height difference $(\Delta h)$ of each transition section exceeds $6 \mathrm{~cm}$, it will have uncomfortable visual experience. So we choose $6 \mathrm{~cm}$ as the height difference of antiglare panels in the transition section to meet the driver's visual continuity and comfort.

\section{Discussion}

The objective of this study is to determine properly the height of antiglare panels in concave vertical curves. And this story focuses on how to set a reasonable transition and determine the height difference of antiglare panels for transition section. If the antiglare panels are too short, they may result in light leakage on concave vertical curve roads, causing the dazzling 
phenomenon. When the antiglare panels are too tall, they will interfere with driver's sight. It should be noted that the heights of antiglare panels in concave vertical curves and straight roads are different for the most part, and large height differences of antiglare panels will decrease driver's comfort.

Based on the experimental results, the height difference should not exceed $6 \mathrm{~cm}$, which applied to all of the transition section. In the future, if engineers need to design the height of the antiglare panels in the transition section, they can directly use this height difference. Notably, when the radius of the concave vertical curve exceeds $30,000 \mathrm{~m}$, the freeway alignment is smooth, and a transition section is not necessary.

According to the visual characteristics of drivers, we divide a concave vertical curve section into three sections. This result is consistent with previous studies that showed that different freeway alignments require different heights of antiglare panels [30]. Those studies used an algorithm to determine the height of antiglare panels in concave vertical curves, but they neglected the abruptness of the height change of the antiglare panels $[31,32]$.

The abundant data and models that are developed in this study have broad applications for vehicle safety and beyond. The proximate motivation for the simulation model is to determine the height difference of antiglare panels in the transition section. The UC-Win/Road software and corresponding driving simulator are used in the simulation process. Notably, our results suggest that drivers will experience visual abruptness when the height difference $(\Delta h)$ of each section in the transition section exceeds $6 \mathrm{~cm}$. Thus, the optimal height difference of the antiglare panels is $6 \mathrm{~cm}$.

Similar to many studies of this type, this study is limited by the characteristics of the drivers. The current sample is not representative of age distributions in China. In particular, older drivers are substantially underrepresented. This study does not include bidirectional 6-lane or bidirectional 8-lane experiments, which should be included as part of future studies. The abruptness is obtained from a simulation environment instead of an on-road environment. In addition, abruptness degree depends on the feelings of individual drivers. Moreover, compared with other antiglare barriers, antiglare panels have their advantages and disadvantages [36]. Thus, future studies should strengthen the current results by investigating the abruptness of the height change of antiglare panels in an on-road driving environment.

\section{Conflicts of Interest}

The authors declare that there are no conflicts of interest regarding the publication of this paper.

\section{Acknowledgments}

This work was supported by Fundamental Research Funds for the Central Universities of China (no. 310821172007, no. 300102218410, no. 300102218521, and no. 300102218409), Natural Science Basic Research Plan in Shaanxi Province of China (no. 2016JM5081), and Science Plan Project of Department of Transport in Shaanxi Province of China (no. 15-27k).
The authors thank Yan Wu, Gaofeng Li, Meiye Li, and Ye Wang for their contributions to this paper.

\section{References}

[1] D. Miller and G. Benedek, Intraocular Light Scattering: Theory and Clinical Application, Charles C. Thomas, Springfield, Ill, USA, 1973.

[2] M. A. Mainster and P. L. Turner, "Glare's causes, consequences, and clinical challenges after a century of ophthalmic study," American Journal of Ophthalmology, vol. 153, no. 4, pp. 587-593, 2012.

[3] T. J. T. P. van den Berg, L. J. van Rijn, R. Kaper-Bongers et al., "Disability glare in the aging eye. Assessment and impact on driving," Journal of Optometry, vol. 2, no. 3, pp. 112-118, 2009.

[4] Y.-Y. Huang and M. Menozzi, "Effects of discomfort glare on performance in attending peripheral visual information in displays," Displays, vol. 35, no. 5, pp. 240-246, 2014.

[5] R. Gray and D. Regan, "Glare susceptibility test results correlate with temporal safety margin when executing turns across approaching vehicles in simulated low-sun conditions," Ophthalmic and Physiological Optics, vol. 27, no. 5, pp. 440-450, 2007.

[6] S. A. Whetsel Borzendowski, A. A. Stafford Sewall, P. J. Rosopa, and R. A. Tyrrell, "Drivers' judgments of the effect of headlight glare on their ability to see pedestrians at night," Journal of Safety Research, vol. 53, pp. 31-37, 2015.

[7] Federal Highway Administration, Manual on Uniform Traffic Control Devices for Streets and Highways. US, 2012.

[8] K. Dunnell, Attitudes to an anti-dazzle fence. Publication of Her Majestys Stationery Office, Publication of Her Majestys Stationery Office, 1976.

[9] Z. B. Sanja, N. Zuber, and A. Sinan, "Road Traffic Safety in Night-Time Conditions as Seen from the Aspect of the problem of Glare," Mednarodno Posvetovanje O Prometni Znanosti, pp. 14-15, 2005.

[10] P. L. Olson and M. Sivak, "Toward the development of a field methodology for evaluating discomfort glare from automobile headlamps," Journal of Safety Research, vol. 19, pp. 135-143, 1988.

[11] J. Theeuwes, J. W. A. M. Alferdinck, and M. Perel, "Relation between glare and driving performance," Human Factors: The Journal of the Human Factors and Ergonomics Society, vol. 44, no. 1, pp. 95-107, 2002.

[12] P. Vayalamkuzhi and V. Amirthalingam, "Influence of geometric design characteristics on safety under heterogeneous traffic flow," Journal of Traffic and Transportation Engineering (English Edition), vol. 3, no. 6, pp. 559-570, 2016.

[13] A. D. Hwang and E. Peli, "Development of a headlight glare simulator for a driving simulator," Transportation Research Part C: Emerging Technologies, vol. 32, pp. 129-143, 2013.

[14] P. K. Kaiser, D. Bodinger, C. Blarney, and F. W. Jung, "Discomfort glare from highway lighting," LEUKOS The Journal of the Illuminating Engineering Society of North America, vol. 10, no. 1, pp. 17-23, 1980.

[15] D. P. Jenkins, L. M. Baker, and C. Harvey, "A practical approach to glare assessment for train cabs," Applied Ergonomics, vol. 47, pp. 170-180, 2015.

[16] Q. Li, F. Qiao, and L. Yu, "Implications of advanced warning messages on eliminating sun glare disturbances at signalized intersections," Journal of Traffic and Transportation Engineering (English Edition), vol. 3, no. 4, pp. 296-307, 2016. 
[17] A. Walker and R. Chapman, "Assessment of anti-dazzle screen on m6," Apwa Reporter, 1980.

[18] C. F. Yang, J. L. Xiao, and J. S. Sun, "The study of the highway glare plate height under mixed traffic," Applied Mechanics and Materials, vol. 193-194, pp. 1017-1020, 2012.

[19] J. V. Musick, "Accident analysis before and after installation of expanded metal glare screen - abridgement," Highway Research Board Special Report, 1970.

[20] Ministry of Transport of the People's Republic of China, General Specification of Freeway Traffic Engineering and Roadside Facilities-JTG D80-2006, China Communications Press, Beijing, China, 2006.

[21] J. S. Gluck and M. R. Lorenz, Transportation Research Board. National cooperative highway research program synthesis of highway practice, Glare Screen Guidelines, Transportation Research Board, Washington, DC, USA, 1979.

[22] "Department of Transport Highways," Roadside Features. HMSO: UK. TA57/87. 1989.

[23] California Department of Transportation, Traffic Manual. California Department of Transportation, 2012.

[24] H. T. Zwahlen and E. Oner, Improved Work Zone Design Guidelines and Enhanced Model of Travel Delays in Work Zones, Ohio Department of Transportation, 2006.

[25] North Carolina Department of Transportation, "Roadway Design Manual. Miscellaneous Design Criteria," North Carolina Department of Transportation, 2013.

[26] N. D. Kodan, National Expressway Practices in Japan, Highway Public Corporation, Tokyo, Japan, 1985.

[27] S. K. Bagui and A. Ghosh, "Glare screen height for unsymmetrical and unequal vertical curves," Indian Highways, vol. 36, no. 4, pp. 33-51, 2009.

[28] C. A. O'Flaherty, Geometric Design of Streets and Highways, Chapter 19, Transport Planning \& Traffic Engineering, 1997.

[29] J. H. Mok, H. C. Landphair, and J. R. Naderi, "Landscape improvement impacts on roadside safety in Texas," Landscape and Urban Planning, vol. 78, no. 3, pp. 263-274, 2006.

[30] S. K. Bagui and A. Ghosh, "Three-dimensional analysis for determination of anti-glare screen barrier height," Jordan Journal of Civil Engineering, vol. 5, no. 4, pp. 468-479, 2011.

[31] H. B. Deng and Z. Liu, "Anti-glare height research of concave vertical curve base on longitudinal glare distance," Highway Engineering, vol. 38, no. 1, pp. 86-89, 2013.

[32] Y. Wu, J. J. Wang, G. B. Cao, and G. H. Liang, "Calculation method of anti-glare plate height on concave vertical curve section," Traffic and Transportation Engineering, vol. 13, no. 2, pp. 86-91, 2013.

[33] J. J. Yang, Y. Y. Peng, G. u. LP, and J. Fu, "Height of anti-dazzle facility based on profile of road," Transportation Standardization, vol. 14, pp. 123-127, 2011.

[34] Ministry of Transport of the People's Republic of China, JTG / TD81-2006. Guidelines for Design of Highway Safety Facilities, China Communications Press, Beijing, China, 2006.

[35] Ministry of Transport of the People's Republic of China, JTG B01-2014. Technical Standard of Highway Engineering, China Communications Press, Beijing, China, 2014.

[36] D. Mace, P. Garvey, R. Porter, R. Schwab, and A. Werner, Countermeasures for Reducing the Effects of Headlight Glare, The AAA Foundation for Traffic Safety, Washington, DC, USA, 2001. 


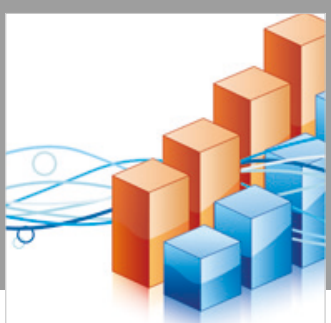

Advances in

Operations Research

\section{-n-m}
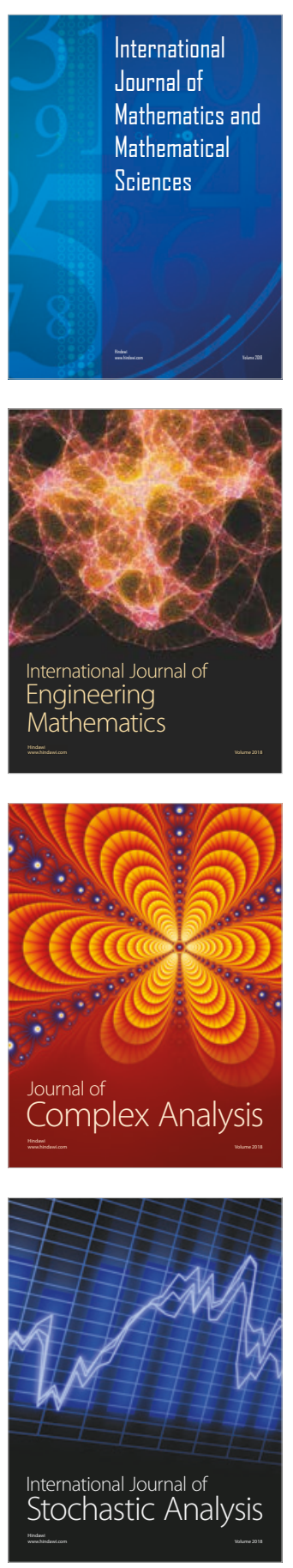
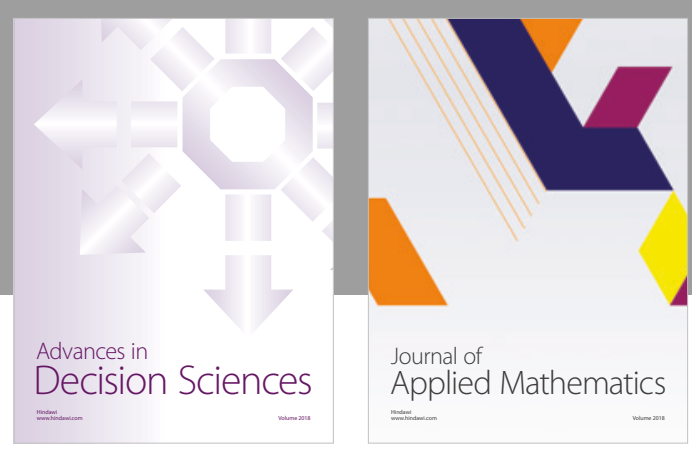

Journal of

Applied Mathematics
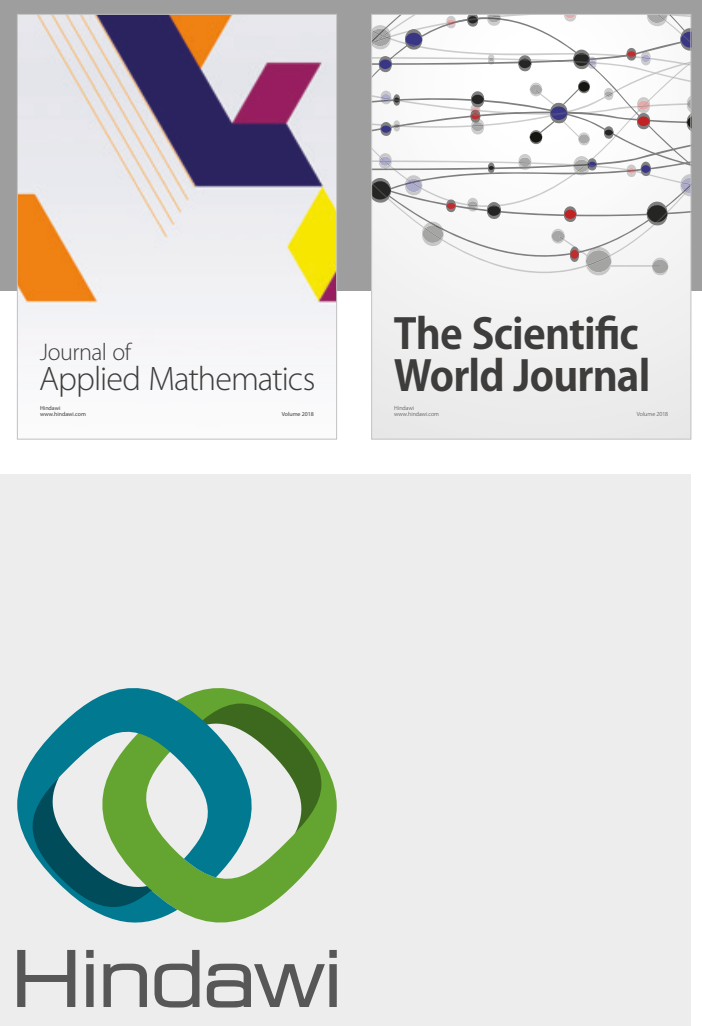

Submit your manuscripts at

www.hindawi.com

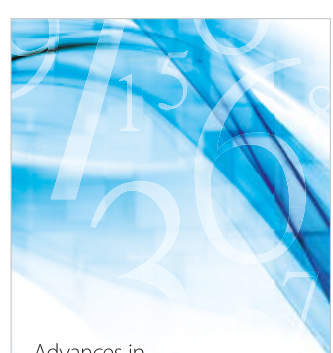

Advances in
Numerical Analysis
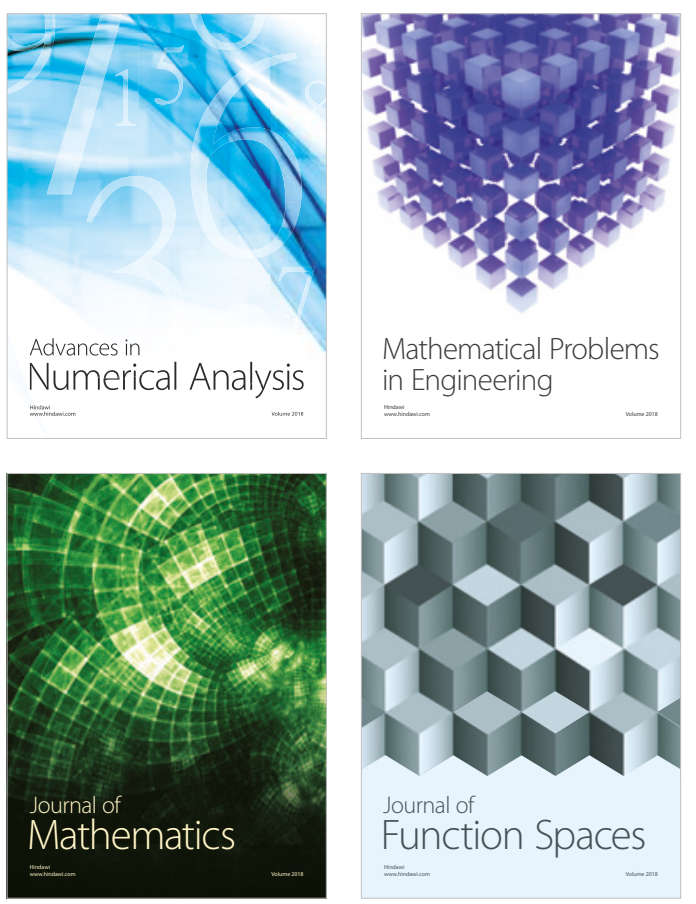

Mathematical Problems in Engineering

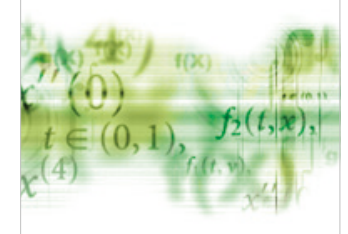

International Journal of

Differential Equations

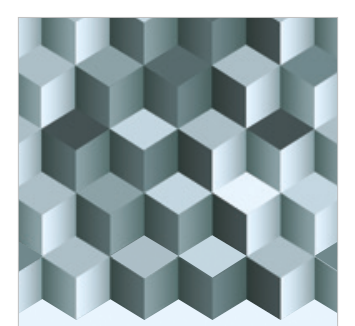

Journal of

Function Spaces

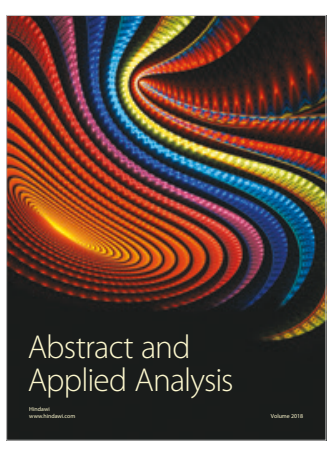

The Scientific

World Journal

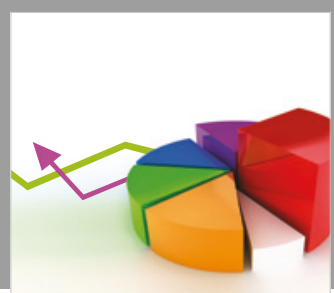

Journal of

Probability and Statistics
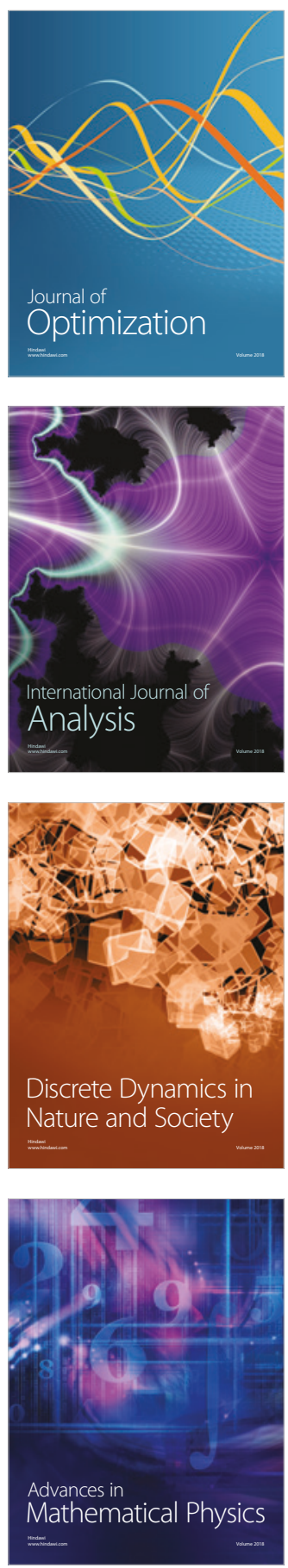